\title{
Some generalized difference statistically convergent sequence spaces in 2-normed space
}

\author{
Metin Başarır', Şükran Konca ${ }^{1 *}$ and Emrah Evren Kara²
}

\section{"Correspondence:}

skonca@sakarya.edu.tr

'Department of Mathematics,

Sakarya University, Sakarya, 54187,

Turkey

Full list of author information is

available at the end of the article

\begin{abstract}
In this paper, we define a new generalized difference matrix $B_{(m)}^{n}$ and introduce some $B_{(m)}^{n}$-difference statistically convergent sequence spaces in a real linear 2-normed space. We also investigate some topological properties of these spaces.

MSC: Primary 40A05; secondary 46A45; 46E30
\end{abstract}

Keywords: statistical convergence; generalized difference sequence space; 2-norm; paranorm; completeness; solidity

\section{Introduction}

We shall write $w$ for the set of all real sequences $x=\left(x_{k}\right)=\left(x_{k}\right)_{k=0}^{\infty}$. Let $c, c_{0}, \bar{c}, \bar{c}_{0}, l_{\infty}, m$ and $m_{0}$ denote the sets of all convergent, null, statistically convergent, statistically null, bounded, bounded statistically convergent and bounded statistically null sequences, respectively. The difference sequence spaces $l_{\infty}(\Delta), c(\Delta)$ and $c_{0}(\Delta)$ were first defined by Kızmaz in [1]. The idea of difference sequences is generalized by Et and Çolak [2] as

$$
Z\left(\Delta^{n}\right)=\left\{x=\left(x_{k}\right) \in w:\left(\Delta^{n} x_{k}\right) \in Z\right\} \quad(n \in \mathbb{N})
$$

for $Z=l_{\infty}, c, c_{0}$, where $\Delta^{n} x_{k}=\Delta^{n-1} x_{k}-\Delta^{n-1} x_{k+1}$ and $\Delta^{0} x_{k}=x_{k}$ for all $k \in \mathbb{N}$, the difference operator is equivalent to the following binomial representation:

$$
\Delta^{n} x_{k}=\sum_{v=0}^{n}(-1)^{v}\left(\begin{array}{l}
n \\
v
\end{array}\right) x_{k+v} .
$$

Et and Başarır [3] generalized these spaces to $E\left(\Delta^{n}\right)$, where $E=l_{\infty}(p), c(p), c_{0}(p)$ are Maddox's sequence spaces. Tripathy and Esi [4], who studied the spaces $l_{\infty}\left(\Delta_{m}\right), c\left(\Delta_{m}\right)$ and $c_{0}\left(\Delta_{m}\right)$, gave a new type of generalization of the difference sequence spaces, where $\Delta_{m} x=\left(\Delta_{m} x_{k}\right)=\left(x_{k}-x_{k+m}\right)$. Tripathy et al. [5] generalized this notion as follows:

$$
Z\left(\Delta_{m}^{n}\right)=\left\{x=\left(x_{k}\right) \in w:\left(\Delta_{m}^{n} x_{k}\right) \in Z\right\} \quad(n, m \in \mathbb{N}),
$$

where $\Delta_{m}^{n} x=\left(\Delta_{m}^{n} x_{k}\right)=\left(\Delta_{m}^{n-1} x_{k}-\Delta_{m}^{n-1} x_{k+m}\right)$ and $\Delta_{m}^{0} x_{k}=x_{k}$ for all $k \in \mathbb{N}$, which is equivalent to the following binomial representation:

$$
\Delta_{m}^{n} x_{k}=\sum_{v=0}^{n}(-1)^{v}\left(\begin{array}{l}
n \\
v
\end{array}\right) x_{k+m v}
$$

( 2013 Başarır et al.; licensee Springer. This is an Open Access article distributed under the terms of the Creative Commons Attribution License (http://creativecommons.org/licenses/by/2.0), which permits unrestricted use, distribution, and reproduction in any medium, provided the original work is properly cited. 
The difference sequence spaces have been studied by several authors, [3, 6-25].

The concept of 2-normed spaces has been initially introduced by Gähler in the 1960s [26], as an interesting non-linear generalization of a normed linear space, which has been subsequently studied by many authors [27-29]. Since then, a lot of activities have been started to study summability, sequence spaces and related topics on 2-normed spaces [3033]. Recently, some difference sequence spaces have been introduced in 2-normed spaces by several authors [30, 31, 34].

Dutta [34] introduced the sequence spaces $\bar{c}\left(\|\cdot, \cdot\|, \Delta_{(m)}^{n}, p\right), \bar{c}_{0}\left(\|\cdot, \cdot\|, \Delta_{(m)}^{n}, p\right), l_{\infty}(\|\cdot, \cdot\|$, $\left.\Delta_{(m)}^{n}, p\right), m\left(\|\cdot, \cdot\|, \Delta_{(m)}^{n}, p\right)$ and $m_{0}\left(\|\cdot, \cdot\|, \Delta_{(m)}^{n}, p\right)$, where $m, n \in \mathbb{N}$ and $\Delta_{(m)}^{n} x=\left(\Delta_{(m)}^{n} x_{k}\right)=$ $\left(\Delta_{(m)}^{n-1} x_{k}-\Delta_{(m)}^{n-1} x_{k-m}\right)$, and $\Delta_{(m)}^{0} x_{k}=x_{k}$ for all $k \in \mathbb{N}$, which is equivalent to the following binomial representation:

$$
\Delta_{(m)}^{n} x_{k}=\sum_{v=0}^{n}(-1)^{v}\left(\begin{array}{l}
n \\
v
\end{array}\right) x_{k-m v}
$$

In [35], Başar and Altay introduced the generalized difference matrix $B(r, s)=\left(b_{n k}(r, s)\right)$ which is a generalization of $\Delta_{(1)}^{1}$-difference operator as follows:

$$
b_{n k}(r, s)= \begin{cases}r & (k=n), \\ s & (k=n-1), \\ 0 & (0 \leq k<n-1) \text { or }(k>n)\end{cases}
$$

for all $k, n \in \mathbb{N}, r, s \in \mathbb{R}-\{0\}$. Recently, Başarır and Kayıkçı [36] have defined the generalized difference matrix $B^{n}$ of order $n$, which reduced the difference operator $\Delta_{(1)}^{n}$ in case $r=1, s=-1$ and the binomial representation of this operator is

$$
B^{n} x_{k}=\sum_{v=0}^{n}\left(\begin{array}{l}
n \\
v
\end{array}\right) r^{n-v} s^{v} x_{k-v}
$$

where $r, s \in \mathbb{R}-\{0\}$ and $n \in \mathbb{N}$.

Thus, for any sequence space $Z$, the space $Z\left(B^{n}\right)$ is more general and more comprehensive than the corresponding consequences of the space $Z\left(\Delta_{(1)}^{n}\right)$. For details, one may refer to $[6,15,35-40]$.

The idea of statistical convergence was given by Zygmund [41] in 1935. The concept of statistical convergence was introduced by Fast [42] and Schoenberg [43], independently for the real sequences. Later on, it was further investigated from sequence point of view and linked with the summability theory by Fridy [44] and generalized to the concept of 2-normed space by Gürdal and Pehlivan [45]. The idea is based on the notion of natural density of subsets of $\mathbb{N}$, the set of positive integers, which is defined as follows: the natural density of a subset $E$ of $\mathbb{N}$ is denoted by

$$
\delta(E)=\lim _{n \rightarrow \infty} \frac{1}{n}|\{k \in E: k \leq n\}|,
$$

where the vertical bar denotes the cardinality of the enclosed set. 


\section{Definitions and preliminaries}

A sequence space $E$ is said to be solid (or normal) if $\left(x_{k}\right) \in E$ implies $\left(\alpha_{k} x_{k}\right) \in E$ for all sequences of scalars $\left(\alpha_{k}\right)$ with $\left|\alpha_{k}\right| \leq 1$ for all $k \in \mathbb{N}$.

A linear topological space $X$ over the real field $R$ is said to be a paranormed space if there is a sub-additive function $g: X \rightarrow R$ such that $g(\theta)=0, g(x)=g(-x), g(x+y) \leq g(x)+g(y)$ and scalar multiplication is continuous, i.e. $\left|\lambda_{n}-\lambda\right| \rightarrow 0$ and $g\left(x_{n}-x\right) \rightarrow 0$ imply that $g\left(\lambda_{n} x_{n}-\lambda x\right) \rightarrow 0$ for all $\lambda$ 's in $\mathbb{R}$ and all $x^{\prime}$ 's in $X$, where $\theta$ is the zero vector in the linear space $X$.

The following inequality will be used throughout the paper:

Let $p=\left(p_{k}\right)$ be a positive sequence of real numbers with $\inf _{k} p_{k}=h, \sup _{k} p_{k}=H$ and $D=\max \left\{1,2^{H-1}\right\}$. Then for all $a_{k}, b_{k} \in \mathbb{C}$ for all $k \in \mathbb{N}$, we have

$$
\left|a_{k}+b_{k}\right|^{p_{k}} \leq D\left\{\left|a_{k}\right|^{p_{k}}+\left|b_{k}\right|^{p_{k}}\right\}
$$

and $|\lambda|^{p_{k}} \leq \max \left\{|\lambda|^{h},|\lambda|^{H}\right\}$ for $\lambda \in \mathbb{C}$.

A 2-norm on a vector space $X$ of $d$ dimension, where $d \geq 2$, is a function $\|\cdot, \cdot\|: X \times X \rightarrow$ $\mathbb{R}$, which satisfies the following conditions:

(1) $\left\|x_{1}, x_{2}\right\|=0$ if and only if $x_{1}, x_{2}$ are linearly dependent,

(2) $\left\|x_{1}, x_{2}\right\|=\left\|x_{2}, x_{1}\right\|$

(3) $\left\|\alpha x_{1}, x_{2}\right\|=|\alpha|\left\|x_{1}, x_{2}\right\|$ for any $\alpha \in \mathbb{R}$,

(4) $\left\|x+x^{\prime}, x_{1}\right\| \leq\left\|x, x_{1}\right\|+\left\|x^{\prime}, x_{1}\right\|$.

The pair $(X,\|\cdot, \cdot\|)$ is then called a 2-normed space. For example, standard and Euclidean 2-norms on $\mathbb{R}^{2}$ are respectively given by

$$
\left\|x_{1}, x_{2}\right\|_{S}=\left|\begin{array}{ll}
\left\langle x_{1}, x_{1}\right\rangle & \left\langle x_{1}, x_{2}\right\rangle \\
\left\langle x_{2}, x_{1}\right\rangle & \left\langle x_{2}, x_{2}\right\rangle
\end{array}\right|^{\frac{1}{2}}
$$

and

$$
\left\|x_{1}, x_{2}\right\|_{E}=\operatorname{abs}\left(\left|\begin{array}{ll}
x_{11} & x_{12} \\
x_{21} & x_{22}
\end{array}\right|\right), \quad x_{i}=\left(x_{i 1}, x_{i 2}\right) \in \mathbb{R}^{2}(i=1,2)
$$

where $\langle\cdot, \cdot\rangle$ stands for the inner product on $X[27]$.

Now we will give the following known example for 2-normed spaces.

Example 2.1 Consider the space $Z$ for $l_{\infty}, c$ and $c_{0}$. Let us define:

$$
\|x, y\|=\sup _{i \in \mathbb{N}} \sup _{j \in \mathbb{N}}\left|x_{i} y_{j}-x_{j} y_{i}\right|
$$

where $x=\left(x_{1}, x_{2}, \ldots\right)$ and $y=\left(y_{1}, y_{2}, \ldots\right) \in Z$. Then $\|\cdot, \cdot\|$ is a 2-norm on $Z$.

A sequence $\left(x_{k}\right)$ in a 2-normed space $(X,\|\cdot, \cdot\|)$ is said to be convergent to some $L \in X$ in the 2-norm if

$$
\lim _{k \rightarrow \infty}\left\|x_{k}-L, z\right\|=0 \quad \text { for every } z \in X[45] .
$$


A sequence $\left(x_{k}\right)$ in a 2-normed space $(X,\|\cdot, \cdot\|)$ is said to be Cauchy sequence with respect to the 2-norm if

$$
\lim _{k, l \rightarrow \infty}\left\|x_{k}-x_{l}, z\right\|=0 \quad \text { for every } z \in X[45]
$$

If every Cauchy sequence in $X$ converges to some $L \in X$, then $X$ is said to be complete with respect to the 2-norm. Any complete 2-normed space is said to be a 2-Banach space [29].

Let recall that a sequence $\left(x_{k}\right)$ is said to be statistically convergent to $L$ if for every $\varepsilon>0$ the set $\left\{k \in \mathbb{N}:\left\|x_{k}-L, z\right\| \geq \varepsilon\right\}$ has natural density zero for each nonzero $z$ in $X$, in other words $\left(x_{k}\right)$ statistically converges to $L$ in 2 -normed space $(X,\|\cdot, \cdot\|)$ if

$$
\lim _{k \rightarrow \infty} \frac{1}{k}\left|\left\{k \in \mathbb{N}:\left\|x_{k}-L, z\right\| \geq \varepsilon\right\}\right|=0,
$$

for each nonzero $z$ in $X$. For $L=0$, we say this is statistically null [45].

Firstly, we give the following lemma, which we need to establish our main results.

Lemma 2.2 [34] Every closed linear subspace $F$ of an arbitrary linear normed space E, different from $E$, is a nowhere dense set in $E$.

Throughout the paper $w(X), c(X), c_{0}(X), \bar{c}(X), \bar{c}_{0}(X), l_{\infty}(X), m(X)$ and $m_{0}(X)$ denote the spaces of all, convergent, null, statistically convergent, statistically null, bounded, bounded statistically convergent and bounded statistically null $X$ valued sequence spaces, where $(X,\|\cdot, \cdot\|)$ is a real 2-normed space. $\operatorname{By} \theta=(\theta, \theta, \theta, \ldots)$, we mean the zero element of $X$.

\section{Main results}

In this section, we define the generalized difference matrix $B_{(m)}^{n}$ and introduce difference sequence spaces $\bar{c}\left(B_{(m)}^{n}, p,\|\cdot, \cdot\|\right), \bar{c}_{0}\left(B_{(m)}^{n}, p,\|\cdot, \cdot\|\right), m\left(B_{(m)}^{n}, p,\|\cdot, \cdot\|\right), m_{0}\left(B_{(m)}^{n}, p,\|\cdot, \cdot\|\right)$, $c\left(B_{(m)}^{n}, p,\|\cdot, \cdot\|\right), c_{0}\left(B_{(m)}^{n}, p,\|\cdot, \cdot\|\right), l_{\infty}\left(B_{(m)}^{n}, p,\|\cdot, \cdot\|\right), W\left(B_{(m)}^{n}, p,\|\cdot, \cdot\|\right)$, which are defined on a real linear 2-normed space. We investigate some topological properties of the spaces $\bar{c}_{0}\left(B_{(m)}^{n}, p,\|\cdot, \cdot\|\right), \bar{c}\left(B_{(m)}^{n}, p,\|\cdot, \cdot\|\right), m\left(B_{(m)}^{n}, p,\|\cdot, \cdot\|\right)$ and $m_{0}\left(B_{(m)}^{n}, p,\|\cdot, \cdot\|\right)$ including linearity, existence of paranorm and solidity. Further, we show that the sequence spaces $m\left(B_{(m)}^{n}, p,\|\cdot, \cdot\|\right)$ and $m_{0}\left(B_{(m)}^{n}, p,\|\cdot, \cdot\|\right)$ are complete paranormed spaces when the base space is a 2-Banach space. Moreover, we give some inclusion relations.

By the notation $x_{k} \stackrel{\text { stat }}{\rightarrow} 0$, we will mean that $x_{k}$ is statistically convergent to zero, throughout the paper. Let $m, n$ be non-negative integers and $p=\left(p_{k}\right)$ be a sequence of strictly positive real numbers. Then we define new sequence spaces as follows:

$$
\begin{aligned}
\bar{c}\left(B_{(m)}^{n}, p,\|\cdot, \cdot\|\right)= & \left\{x=\left(x_{k}\right) \in w(X):\left\|B_{(m)}^{n} x_{k}-L, z\right\|^{p_{k}} \stackrel{\text { stat }}{\rightarrow} 0,\right. \\
& \text { for every nonzero } z \in X \text { and some } L \in X\}, \\
\bar{c}_{0}\left(B_{(m)}^{n}, p,\|\cdot, \cdot\|\right)= & \left\{x=\left(x_{k}\right) \in w(X):\left\|B_{(m)}^{n} x_{k}, z\right\|^{p_{k}} \stackrel{\text { stat }}{\rightarrow} 0, \text { for every nonzero } z \in X\right\}, \\
l_{\infty}\left(B_{(m)}^{n}, p,\|\cdot, \cdot\|\right)= & \left\{x=\left(x_{k}\right) \in w(X): \sup _{k \geq 1}\left(\left\|B_{(m)}^{n} x_{k}, z\right\|^{p_{k}}\right)<\infty,\right. \\
& \text { for every nonzero } z \in X\},
\end{aligned}
$$




$$
\begin{aligned}
& c\left(B_{(m)}^{n}, p,\|\cdot, \cdot\|\right)=\left\{x=\left(x_{k}\right): \lim _{k \rightarrow \infty}\left\|B_{(m)}^{n} x_{k}-L, z\right\|^{p_{k}}=0,\right. \\
& \text { for every nonzero } z \in X \text { and some } L \in X\} \text {, } \\
& c_{0}\left(B_{(m)}^{n}, p,\|\cdot, \cdot\|\right)=\left\{x=\left(x_{k}\right): \lim _{k \rightarrow \infty}\left\|B_{(m)}^{n} x_{k}, z\right\|^{p_{k}}=0 \text {, for every nonzero } z \in X\right\} \text {, } \\
& W\left(B_{(m)}^{n}, p,\|\cdot, \cdot\|\right)=\left\{x=\left(x_{k}\right) \in w(X): \lim _{j \rightarrow \infty} \frac{1}{j} \sum_{k=1}^{j}\left\|B_{(m)}^{n} x_{k}-L, z\right\|^{p_{k}}=0,\right. \\
& \text { for every nonzero } z \in X \text { and some } L \in X\} \text {, } \\
& m\left(B_{(m)}^{n}, p,\|\cdot, \cdot\|\right)=\bar{c}\left(B_{(m)}^{n}, p,\|\cdot, \cdot\|\right) \cap l_{\infty}\left(B_{(m)}^{n}, p,\|\cdot, \cdot\|\right)
\end{aligned}
$$

and

$$
m_{0}\left(B_{(m)}^{n}, p,\|\cdot, \cdot\|\right)=\bar{c}_{0}\left(B_{(m)}^{n}, p,\|\cdot, \cdot\|\right) \cap l_{\infty}\left(B_{(m)}^{n}, p,\|\cdot, \cdot\|\right)
$$

where $B_{(m)}^{n} x=B_{(m)}^{n} x_{k}=r B_{(m)}^{n-1} x_{k}+s B_{(m)}^{n-1} x_{k-m}$ and $B_{(m)}^{0} x_{k}=x_{k}$ for all $k \in \mathbb{N}$, which is equivalent to the binomial representation as follows:

$$
B_{(m)}^{n} x_{k}=\sum_{v=0}^{n}\left(\begin{array}{l}
n \\
v
\end{array}\right) r^{n-v} s^{v} x_{k-m v} .
$$

In this representation, we obtain the matrix $B_{(1)}^{n}$ defined in [36] for $n>1$ and in [35] for $n=1$.

(1) If we take $n=0$ then the above sequence spaces are reduced to $\bar{c}(p,\|\cdot, \cdot\|)$, $\bar{c}_{0}(p,\|\cdot, \cdot\|), l_{\infty}(p,\|\cdot, \cdot\|), c(p,\|\cdot, \cdot\|), c_{0}(p,\|\cdot, \cdot\|), W(p,\|\cdot, \cdot\|), m(p,\|\cdot, \cdot\|)$ and $m_{0}(p,\|\cdot, \cdot\|)$, respectively.

(2) If we take $r=1, s=-1$, then the sequence spaces $\bar{c}\left(B_{(m)}^{n}, p,\|\cdot, \cdot\|\right), \bar{c}_{0}\left(B_{(m)}^{n}, p,\|\cdot, \cdot\|\right)$, $l_{\infty}\left(B_{(m)}^{n}, p,\|\cdot, \cdot\|\right), W\left(B_{(m)}^{n}, p,\|\cdot, \cdot\|\right), m\left(B_{(m)}^{n}, p,\|\cdot, \cdot\|\right), m_{0}\left(B_{(m)}^{n}, p,\|\cdot, \cdot\|\right)$ are reduced to $\bar{c}\left(\Delta_{(m)}^{n}, p,\|\cdot, \cdot\|\right), \bar{c}_{0}\left(\Delta_{(m)}^{n}, p,\|\cdot, \cdot\|\right), l_{\infty}\left(\Delta_{(m)}^{n}, p,\|\cdot, \cdot\|\right), W\left(\Delta_{(m)}^{n}, p,\|\cdot, \cdot\|\right)$, $m\left(\Delta_{(m)}^{n}, p,\|\cdot, \cdot\|\right)$ and $m_{0}\left(\Delta_{(m)}^{n}, p,\|\cdot, \cdot\|\right)$, respectively, which are studied in [34].

(3) By taking $p_{k}=1$ for all $k \in \mathbb{N}$, then these sequence spaces are denoted by $\bar{c}\left(B_{(m)}^{n},\|\cdot, \cdot\|\right), \bar{c}_{0}\left(B_{(m)}^{n},\|\cdot, \cdot\|\right), l_{\infty}\left(B_{(m)}^{n},\|\cdot, \cdot\|\right), c\left(B_{(m)}^{n},\|\cdot, \cdot\|\right), c_{0}\left(B_{(m)}^{n},\|\cdot, \cdot\|\right)$, $W\left(B_{(m)}^{n},\|\cdot, \cdot\|\right), m\left(B_{(m)}^{n},\|\cdot, \cdot\|\right)$ and $m_{0}\left(B_{(m)}^{n},\|\cdot, \cdot\|\right)$, respectively.

(4) If we replace the base space $X$, which is a real linear 2 -normed space by $\mathbb{C}$, complete normed linear space, and take $m=1$ and take $r=1, s=-1$, then the above sequence spaces are denoted by $\bar{c}\left(\Delta_{(1)}^{n}, p\right), \bar{c}_{0}\left(\Delta_{(1)}^{n}, p\right), l_{\infty}\left(\Delta_{(1)}^{n}, p\right), c\left(\Delta_{(1)}^{n}, p\right), c_{0}\left(\Delta_{(1)}^{n}, p\right)$, $W\left(\Delta_{(1)}^{n}, p\right), m\left(\Delta_{(1)}^{n}, p\right)$ and $m_{0}\left(\Delta_{(1)}^{n}, p\right)$, respectively.

(5) If we take $r=1, s=-1, p_{k}=1$ for all $k \in \mathbb{N}$, then these sequence spaces are denoted by $\bar{c}\left(\Delta_{(m)}^{n},\|\cdot, \cdot\|\right), \bar{c}_{0}\left(\Delta_{(m)}^{n},\|\cdot, \cdot\|\right), l_{\infty}\left(\Delta_{(m)}^{n},\|\cdot, \cdot\|\right), c\left(\Delta_{(m)}^{n},\|\cdot, \cdot\|\right), c_{0}\left(\Delta_{(m)}^{n},\|\cdot, \cdot\|\right)$, $W\left(\Delta_{(m)}^{n},\|\cdot, \cdot\|\right), m\left(\Delta_{(m)}^{n},\|\cdot, \cdot\|\right)$ and $m_{0}\left(\Delta_{(m)}^{n}, p,\|\cdot, \cdot\|\right)$, respectively.

(6) If we replace the base space $X$, which is a real linear 2-normed space by $\mathbb{C}$, we obtain the spaces $\bar{c}\left(B_{(m)}^{n}, p\right), \bar{c}_{0}\left(B_{(m)}^{n}, p\right), l_{\infty}\left(B_{(m)}^{n}, p\right), c\left(B_{(m)}^{n}, p\right), c_{0}\left(B_{(m)}^{n}, p\right), W\left(B_{(m)}^{n}, p\right)$, $m\left(B_{(m)}^{n}, p\right)$ and $m_{0}\left(B_{(m)}^{n}, p\right)$, respectively.

(7) Moreover, if we take $X=\mathbb{C}, n=0$ and $p_{k}=1$ for all $k \in \mathbb{N}$, we get the spaces $\bar{c}, \bar{c}_{0}, l_{\infty}$, $c, c_{0}, W, m$ and $m_{0}$, respectively. 
Theorem 3.1 Let $p=\left(p_{k}\right)$ be a sequence of strictly positive real numbers. Then the sequence spaces $Z\left(B_{(m)}^{n}, p,\|\cdot, \cdot\|\right)$ are linear spaces where $Z=\bar{c}, \bar{c}_{0}, l_{\infty}, W, m, m_{0}$.

Proof The proof of the theorem can be obtained by similar techniques in [34].

Theorem 3.2 For any two sequences $p=\left(p_{k}\right)$ and $t=\left(t_{k}\right)$ of positive real numbers and for any two 2-norms $\|\cdot, \cdot\|_{1}$ and $\|\cdot, \cdot\|_{2}$ on $X$ we have $Z\left(B_{(m)}^{n}, p,\|\cdot, \cdot\|_{1}\right) \cap Z\left(B_{(m)}^{n}, p,\|\cdot, \cdot\|_{2}\right) \neq \varnothing$, where $Z=\bar{c}, \bar{c}_{0}, m, m_{0}$.

Proof The proof follows from the fact that the zero element belongs to each of the sequence spaces involved in the intersection.

Theorem 3.3 Let $(X,\|\cdot, \cdot\|)$ be a 2-Banach space. Then the spaces $m\left(B_{(m)}^{n}, p,\|\cdot, \cdot\|\right)$, $m_{0}\left(B_{(m)}^{n}, p,\|\cdot, \cdot\|\right)$ are complete paranormed sequence spaces, paranormed by

$$
g(x)=\sup _{k \in \mathbb{N}, z \in X}\left(\left\|B_{(m)}^{n} x_{k}, z\right\|^{\frac{p_{k}}{M}}\right)
$$

where $M=\max \{1, H\}$ and $H=\sup _{k} p_{k}, h=\inf _{k} p_{k}$.

Proof We will prove the theorem for the sequence space $m_{0}\left(B_{(m)}^{n}, p,\|\cdot, \cdot\|\right)$. It can be proved for the space $m\left(B_{(m)}^{n}, p,\|\cdot, \cdot\|\right)$ similarly.

Clearly $g(-x)=g(x)$ and $g(\theta)=0$. From the following inequality, we have

$$
\begin{aligned}
g(x+y) & =\sup _{k \in \mathbb{N}, z \in X}\left(\left\|B_{(m)}^{n}\left(x_{k}+y_{k}\right), z\right\|^{\frac{p_{k}}{M}}\right) \\
& \leq \sup _{k \in \mathbb{N}, z \in X}\left(\left\|B_{(m)}^{n} x_{k}, z\right\|^{\frac{p_{k}}{M}}\right)+\sup _{k \in \mathbb{N}, z \in X}\left(\left\|B_{(m)}^{n} y_{k}, z\right\|^{\frac{p_{k}}{M}}\right) .
\end{aligned}
$$

This implies that $g(x+y) \leq g(x)+g(y)$.

To prove the continuity of scalar multiplication, assume that $\left(x^{n}\right)$ be any sequence of the points in $m_{0}\left(B_{(m)}^{n}, p,\|\cdot, \cdot\|\right)$ such that $g\left(x^{n}-x\right) \rightarrow 0$ and $\left(\lambda_{n}\right)$ be any sequence of scalars such that $\lambda_{n} \rightarrow \lambda$. Since the inequality

$$
g\left(x^{n}\right) \leq g(x)+g\left(x^{n}-x\right)
$$

holds by subadditivity of $g,\left(g\left(x^{n}\right)\right)$ is bounded. Thus, we have

$$
\begin{aligned}
g\left(\lambda_{n} x^{n}-\lambda x\right)= & \sup _{k \in \mathbb{N}, z \in X}\left(\left\|B_{(m)}^{n} \lambda_{n} x_{k}^{n}-\lambda x_{k}, z\right\|^{\frac{p_{k}}{M}}\right) \\
\leq & \left(\max \left\{\left|\lambda_{n}-\lambda\right|^{h},\left|\lambda_{n}-\lambda\right|^{H}\right\}\right)^{\frac{1}{M}} \sup _{k \in \mathbb{N}, z \in X}\left(\left\|B_{(m)}^{n} x_{k}, z\right\|^{\frac{p_{k}}{M}}\right) \\
& +\left(\max \left\{|\lambda|^{h},|\lambda|^{H}\right\}\right)^{\frac{1}{M}} \sup _{k \in \mathbb{N}, z \in X}\left(\left\|B_{(m)}^{n}\left(x_{k}^{n}-x\right), z\right\|^{\frac{p_{k}}{M}}\right) \\
= & \left(\max \left\{\left|\lambda_{n}-\lambda\right|^{h},\left|\lambda_{n}-\lambda\right|^{H}\right\}\right)^{\frac{1}{M}} g\left(x^{n}\right) \\
& +\left(\max \left\{|\lambda|^{h},|\lambda|^{H}\right\}\right)^{\frac{1}{M}} g\left(x^{n}-x\right)
\end{aligned}
$$


which tends to zero as $n \rightarrow \infty$. Hence, $g$ is a paranorm on the sequence space $m_{0}\left(B_{(m)}^{n}, p\right.$, $\|\cdot, \cdot\|)$.

To prove that $m_{0}\left(B_{(m)}^{n}, p,\|\cdot, \cdot\|\right)$ is complete, assume that $\left(x^{i}\right)$ is a Cauchy sequence in $m_{0}\left(B_{(m)}^{n}, p,\|\cdot, \cdot\|\right)$. Then for a given $\varepsilon(0<\varepsilon<1)$, there exists a positive integer $N_{0}$ such that $g\left(x^{i}-x^{j}\right)<\varepsilon$, for all $i, j \geq N_{0}$. This implies that

$$
\sup _{k \in \mathbb{N}, z \in X}\left(\left\|B_{(m)}^{n} x_{k}^{i}-B_{(m)}^{n} x_{k}^{j}, z\right\|^{\frac{p_{k}}{M}}\right)<\varepsilon
$$

for all $i, j \geq N_{0}$. It follows that for every nonzero $z \in X$,

$$
\left\|B_{(m)}^{n} x_{k}^{i}-B_{(m)}^{n} x_{k}^{j}, z\right\|<\varepsilon
$$

for each $k \geq 1$ and for all $i, j \geq N_{0}$. Hence $\left(B_{(m)}^{n} x_{k}^{i}\right)$ is a Cauchy sequence in $X$ for all $k \in \mathbb{N}$. Since $X$ is a 2-Banach space, $\left(B_{(m)}^{n} x_{k}^{i}\right)$ is convergent in $X$ for all $k \in \mathbb{N}$, so we write $\left(B_{(m)}^{n} x_{k}^{i}\right) \rightarrow\left(B_{(m)}^{n} x_{k}\right)$ as $i \rightarrow \infty$. Now we have for all $i, j \geq N_{0}$,

$$
\begin{aligned}
& \sup _{k \in \mathbb{N}, z \in X}\left(\left\|B_{(m)}^{n}\left(x_{k}^{i}-x_{k}^{j}\right), z\right\|^{\frac{p_{k}}{M}}\right)<\varepsilon \\
& \Rightarrow \lim _{j \rightarrow \infty}\left\{\sup _{k \in \mathbb{N}, z \in X}\left(\left\|B_{(m)}^{n}\left(x_{k}^{i}-x_{k}^{j}\right), z\right\|^{\frac{p_{k}}{M}}\right)\right\}<\varepsilon \\
& \Rightarrow \sup _{k \in \mathbb{N}, z \in X}\left(\left\|B_{(m)}^{n}\left(x_{k}^{i}-x_{k}\right), z\right\|^{\frac{p_{k}}{M}}\right)<\varepsilon,
\end{aligned}
$$

for all $i \geq N_{0}$. It follows that $\left(x^{i}-x\right) \in m_{0}\left(B_{(m)}^{n}, p,\|\cdot, \cdot\|\right)$. Since $\left(x^{i}\right) \in m_{0}\left(B_{(m)}^{n}, p,\|\cdot, \cdot\|\right)$ and $m_{0}\left(B_{(m)}^{n}, p,\|\cdot, \cdot\|\right)$ is a linear space, so we have $x=x^{i}-\left(x^{i}-x\right) \in m_{0}\left(B_{(m)}^{n}, p,\|\cdot, \cdot\|\right)$. This completes the proof.

\section{Theorem 3.4}

(1) If $Z_{1} \subset Z_{2}$, then $Z_{1}\left(B_{(m)}^{n}, p,\|\cdot, \cdot\|\right) \subset Z_{2}\left(B_{(m)}^{n}, p,\|\cdot, \cdot\|\right)$ and the inclusion is strict, where $Z_{1}, Z_{2}=c, c_{0}, l_{\infty}$.

(2) If $n_{1}<n_{2}$, then $Z\left(B_{(m)}^{n_{1}}, p,\|\cdot, \cdot\|\right) \subset Z\left(B_{(m)}^{n_{2}}, p,\|\cdot, \cdot\|\right)$ and the inclusion is strict, where $Z=c, c_{0}, l_{\infty}$.

Proof The parts of proof $Z_{1}\left(B_{(m)}^{n}, p,\|\cdot, \cdot\|\right) \subset Z_{2}\left(B_{(m)}^{n}, p,\|\cdot, \cdot\|\right)$ and $Z_{1}\left(B_{(m)}^{n_{1}}, p,\|\cdot, \cdot\|\right) \subset$ $Z_{2}\left(B_{(m)}^{n_{2}}, p,\|\cdot, \cdot\|\right)$ are easy. To show the inclusions are strict, choose $Z_{1}=c_{0}, Z_{2}=c$, $x=\left(x_{k}\right)=\left(k^{2}, k^{2}\right)$ and consider the 2-norm as defined in (2.1), let $p_{k}=1$ for all $k \in \mathbb{N}$, $m=1, n=2, r=1, s=-1$, then $x \in c\left(B_{(1)}^{2},\|\cdot, \cdot\|\right)$ but $x \notin c_{0}\left(B_{(1)}^{2},\|\cdot, \cdot\|\right)$. If we choose $Z=c$, $x=\left(x_{k}\right)=\left(k^{2}, k^{2}\right)$ and $p_{k}=1$ for all $k \in \mathbb{N}, m=1, n=2, r=1, s=-1$, then $x \in c\left(B_{(1)}^{2},\|\cdot, \cdot\|\right)$ but $x \notin c\left(B_{(1)}^{1},\|\cdot, \cdot\|\right)$. These complete the proofs of parts (1) and (2) of the theorem, respectively.

\section{Theorem 3.5}

(1) $c\left(B_{(m)}^{n},\|\cdot, \cdot\|\right) \subset \bar{c}\left(B_{(m)}^{n},\|\cdot, \cdot\|\right)$ and the inclusion is strict.

(2) $\bar{c}(\|\cdot, \cdot\|) \subset \bar{c}\left(B_{(m)}^{n},\|\cdot, \cdot\|\right)$ and the inclusion is strict.

(3) $\bar{c}\left(B_{(m)}^{n},\|\cdot, \cdot\|\right)$ and $l_{\infty}\left(B_{(m)}^{n},\|\cdot, \cdot\|\right)$ overlap but neither one contains the other. 
(1) It is clear that $c\left(B_{(m)}^{n},\|\cdot, \cdot\|\right) \subset \bar{c}\left(B_{(m)}^{n},\|\cdot, \cdot\|\right)$. To show that the inclusion is strict, choose the sequence $x=\left(x_{k}\right)$ such that,

$$
B_{(m)}^{n} x_{k}= \begin{cases}(0, \sqrt{k}), & k=n^{2}, \\ (0,0), & k \neq n^{2},\end{cases}
$$

where $n \in \mathbb{N}-\{0\}$, and consider the 2-norm as defined in (2.1). Then we obtain $B_{(m)}^{n} x_{k} \in \bar{c}(\|\cdot, \cdot\|)$, but $B_{(m)}^{n} x_{k} \notin c(\|\cdot, \cdot\|)$. That is, $x_{k} \in \bar{c}\left(B_{(m)}^{n}, p,\|\cdot, \cdot\|\right)$, but $x_{k} \notin c\left(B_{(m)}^{n}, p,\|\cdot, \cdot\|\right)$.

(2) It is easy to see that $\bar{c}(\|\cdot, \cdot\|) \subset \bar{c}\left(B_{(m)}^{n},\|\cdot, \cdot\|\right)$. To show that the inclusion is strict, let us take $x=\left(x_{k}\right)=(k, k)$ and consider the 2-norm as defined in (2.1), $m=1, n=1$, $r=1, s=-1$, then $x \in \bar{c}\left(B_{(1)}^{1},\|\cdot, \cdot\|\right)$ but $x \notin \bar{c}(\|\cdot, \cdot\|)$.

(3) Since the sequence $x=\theta$ belongs to each of the sequence spaces, the overlapping part of the proof is obvious. For the other part of the proof, consider the sequence defined by (3.2) and the 2-norm as defined in (2.1). Then $\left.x \in \bar{c}\left(B_{(m)}^{n}\right),\|\cdot, \cdot\|\right)$, but $x \notin l_{\infty}\left(B_{(m)}^{n},\|\cdot, \cdot\|\right)$. Conversely if we choose $\left(B_{(m)}^{n} x_{k}\right)=(\overline{1}, \overline{0}, \overline{1}, \overline{0}, \ldots)$ where $\bar{k}=(k, k)$ for all $k=0,1$, then $B_{(m)}^{n} x_{k} \in l_{\infty}(\|\cdot, \cdot\|)$ but $B_{(m)}^{n} x_{k} \notin \bar{c}(\|\cdot, \cdot\|)$. That is, $x \in l_{\infty}\left(B_{(m)}^{n},\|\cdot, \cdot\|\right)$ but $x \notin \bar{c}\left(B_{(m)}^{n},\|\cdot, \cdot\|\right)$.

Theorem 3.6 The space $Z\left(B_{(m)}^{n}, p,\|\cdot, \cdot\|\right)$ is not solid in general, where $Z=\bar{c}, \bar{c}_{0}, m, m_{0}$.

Proof To show that the space is not solid in general, consider the following examples.

Example 3.7 Let $m=3, n=1, r=1, s=-1$ and consider the 2-normed space as defined in Example 2.1. Let $p_{k}=5$ for all $k \in \mathbb{N}$. Consider the sequence $\left(x_{k}\right)$, where $x_{k}=\left(x_{k}^{i}\right)$ is defined by $\left(x_{k}^{i}\right)=(k, k, k, \ldots)$ for each fixed $k \in \mathbb{N}$. Then $x_{k} \in Z\left(B_{(3)}^{1}, p,\|\cdot, \cdot\|\right)$ for $Z=\bar{c}, m$. Let $\alpha_{k}=(-1)^{k}$, then $\left(\alpha_{k} x_{k}\right) \notin Z\left(B_{(3)}^{1}, p,\|\cdot, \cdot\|\right)$ for $Z=\bar{c}, m$. Thus $Z\left(B_{(3)}^{1}, p,\|\cdot, \cdot\|\right)$ for $Z=\bar{c}, m$ is not solid in general.

Example 3.8 Let $m=3, n=1, r=1, s=-1$ and consider the 2-normed space as defined in Example 2.1. Let $p_{k}=1$ for all odd $k$ and $p_{k}=2$ for all even $k$. Consider the sequence $\left(x_{k}\right)$, where $x_{k}=\left(x_{k}^{i}\right)$ is defined by $\left(x_{k}^{i}\right)=(3,3,3, \ldots)$ for each fixed $k \in \mathbb{N}$. Then $x_{k} \in$ $Z\left(B_{(3)}^{1}, p,\|\cdot, \cdot\|\right)$ for $Z=\bar{c}_{0}, \bar{m}_{0}$. Let $\alpha_{k}=(-1)^{k}$, then $\left(\alpha_{k} x_{k}\right) \notin Z\left(B_{(3)}^{1}, p,\|\cdot, \cdot\|\right)$ for $Z=\bar{c}_{0}, \bar{m}_{0}$. Thus $Z\left(B_{(3)}^{1}, p,\|\cdot, \cdot\|\right)$ for $Z=\bar{c}_{0}, \bar{m}_{0}$ is not solid in general.

Theorem 3.9 The spaces $m_{0}\left(B_{(m)}^{n}, p,\|\cdot, \cdot\|\right)$ and $m\left(B_{(m)}^{n}, p,\|\cdot, \cdot\|\right)$ are nowhere dense subsets of $l_{\infty}\left(B_{(m)}^{n}, p,\|\cdot, \cdot\|\right)$.

Proof From Theorem 3.3, it follows that $m_{0}\left(B_{(m)}^{n}, p,\|\cdot, \cdot\|\right)$ and $m\left(B_{(m)}^{n}, p,\|\cdot, \cdot\|\right)$ are closed subspaces of $l_{\infty}\left(B_{(m)}^{n}, p,\|\cdot, \cdot\|\right)$. Since the inclusion relations

$$
m_{0}\left(B_{(m)}^{n}, p,\|\cdot, \cdot\|\right) \subset l_{\infty}\left(B_{(m)}^{n}, p,\|\cdot, \cdot\|\right), \quad m\left(B_{(m)}^{n}, p,\|\cdot, \cdot\|\right) \subset l_{\infty}\left(B_{(m)}^{n}, p,\|\cdot, \cdot\|\right)
$$

are strict, the spaces $m_{0}\left(B_{(m)}^{n}, p,\|\cdot, \cdot\|\right)$ and $m\left(B_{(m)}^{n}, p,\|\cdot, \cdot\|\right)$ are nowhere dense subsets of $l_{\infty}\left(B_{(m)}^{n}, p,\|\cdot, \cdot\|\right)$ by Lemma 2.2 . 
Theorem 3.10 Let $p=\left(p_{k}\right)$ be a sequence of non-negative bounded real numbers such that $\inf _{k} p_{k}>0$. Then

$$
W\left(B_{(m)}^{n}, p,\|\cdot, \cdot\|\right) \cap l_{\infty}\left(B_{(m)}^{n}, p,\|\cdot, \cdot\|\right) \subset m\left(B_{(m)}^{n}, p,\|\cdot, \cdot\|\right) .
$$

Proof Let $\left(x_{k}\right) \in W\left(B_{(m)}^{n}, p,\|\cdot, \cdot\|\right) \cap l_{\infty}\left(B_{(m)}^{n}, p,\|\cdot, \cdot\|\right)$. Then for a given $\varepsilon>0$, we have

$$
\begin{aligned}
\frac{1}{j} \sum_{k=1}^{j}\left\|B_{(m)}^{n} x_{k}-L, z\right\|^{p_{k}} & \geq \frac{1}{j} \sum_{\substack{k=1 \\
\left\|B_{(m)}^{n} x_{k}-L, z\right\|^{p_{k} \geq \varepsilon}}}^{j}\left\|B_{(m)}^{n} x_{k}-L, z\right\|^{p_{k}} \\
& \geq \varepsilon \frac{1}{j}\left|\left\{k \leq j:\left\|B_{(m)}^{n} x_{k}-L, z\right\|^{p_{k}} \geq \varepsilon\right\}\right| .
\end{aligned}
$$

If we take the limit for $j \rightarrow \infty$, it follows that $\left(x_{k}\right) \in c\left(B_{(m)}^{n}, p,\|\cdot, \cdot\|\right)$ from the inequality above. Since $\left(x_{k}\right) \in l_{\infty}\left(B_{(m)}^{n}, p,\|\cdot, \cdot\|\right)$, we have the result.

\section{Competing interests}

The authors declare that they have no competing interests.

\section{Authors' contributions}

All authors contributed equally in the preparation of this article. All authors read and approved the final manuscript.

\section{Author details}

${ }^{1}$ Department of Mathematics, Sakarya University, Sakarya, 54187, Turkey. ${ }^{2}$ Department of Mathematics, Bilecik Şeyh Edebali University, Bilecik, 11200, Turkey.

\section{Acknowledgements}

Dedicated to Professor Hari M Srivastava.

The authors would like to thank the anonymous reviewers for their comments and suggestions to improve the quality of the paper.

Received: 12 December 2012 Accepted: 2 April 2013 Published: 16 April 2013

\section{References}

1. Kızmaz, H: On certain sequence spaces. Can. Math. Bull. 24(2), 169-176 (1981)

2. Et, M, Çolak, R: On generalized difference sequence spaces. Soochow J. Math. 21(4), 377-386 (1995)

3. Et, M, Başarır, M: On some new generalized difference sequence spaces. Period. Math. Hung. 35(3), 169-175 (1997)

4. Tripathy, BC, Esi, A: A new type of difference sequence spaces. Int. J. Sci. Technol. 1(1), 11-14 (2006)

5. Tripathy, BC, Esi, A, Tripathy, BK: On a new type of generalized difference cesaro sequence spaces. Soochow J. Math. 31(3), 333-340 (2005)

6. Başarır, M, Nuray, F: Paranormed difference sequence spaces generated by infinite matrices. Pure Appl. Math. Sci. 34(1-2), 87-90 (1991)

7. Dutta, H: On some $n$-normed linear space valued difference sequences. J. Franklin Inst. 348(10), 2876-2883 (2011)

8. Dutta, H, Reddy, BS: On non-standard n-norm on some sequence spaces. Int. J. Pure Appl. Math. 68(1), 1-11 (2011)

9. Dutta, $\mathrm{H}$ : On $n$-normed linear space valued strongly $(C, 1)$-summable difference sequences. Asian-Europ. J. Math. 3(4), 565-575 (2010)

10. Dutta, H: On sequence spaces with elements in a sequence of real linear $n$-normed spaces. Appl. Math. Lett. 23(9), 1109-1113 (2010)

11. Dutta, H: An application of lacunary summability method to n-norm. Int. J. Appl. Math. Stat. 15(09), 89-97 (2009)

12. Dutta, $\mathrm{H}$ : Characterization of certain matrix classes involving generalized difference summability spaces. Appl. Sci. 11 , 60-67 (2009)

13. Işık, M: On statistical convergence of generalized difference sequences. Soochow J. Math. 30(2), 197-205 (2004)

14. Karakaya, V, Dutta, H: On some vector valued generalized difference modular sequence spaces. Filomat 25(3), 15-27 (2011)

15. Kirişçi, M, Başar, F: Some new sequence spaces derived by the domain of generalized diffrence matrix. Comput. Math. Appl. 60(5), 1299-1309 (2010)

16. Malkowsky, E, Parashar, SD: Matrix transformations in spaces of bounded and convergent difference sequences of order m. Analysis 17(1), 87-97 (1997)

17. Malkowsky, E, Mursaleen, M, Suantai, S: The dual spaces of sets of difference sequences of order $m$ and matrix transformations. Acta Math. Sin. 23(3), 521-532 (2007) 
18. Mursaleen, M, Noman, AK: On some new difference sequence spaces of non-absolute type. Math. Comput. Model. 52(3-4), 603-617 (2010)

19. Mursaleen, $M$, Karakaya, $V$, Polat, $H$, Şimşek, N: Measure of noncompactness of matrix operators on some difference sequence spaces of weighted means. Comput. Math. Appl. 62(2), 814-820 (2011)

20. Mursaleen, M: Generalized spaces of difference sequences. J. Math. Anal. Appl. 203, 738-745 (1996)

21. Mursaleen, M, Noman, AK: Compactness of matrix operators on some new difference sequence spaces. Linear Algebra Appl. 436(1), 41-52 (2012)

22. Polat, H, Başar, F: Some Euler spaces of difference sequences of order m. Acta Math. Sci. 27(2), $254-266$ (2007)

23. Polat, H, Başarır, M: New Taylor difference sequence spaces of order m. Int. Math. J. 5(3), 211-223 (2004)

24. Tripathy, BC, Dutta, H: On some lacunary difference sequence spaces defined by a sequence of Orlicz functions and q-lacunary $\Delta_{m}^{n}$-statistical convergence. An. Stiint. Univ. Ovidius Constanta, Ser. Mat. 20(1), 417-430 (2012)

25. Tripathy, BC, Dutta, H: On some new paranormed difference sequence spaces defined by Orlicz functions. Kyungpook Math. J. 20(1), 417-430 (2012)

26. Gähler, S: Lineare 2-normierte Raume. Math. Nachr. 28, 1-43 (1964)

27. Gunawan, H, Mashadi, M: On finite dimensional 2-normed spaces. Soochow J. Math. 27(3), 321-329 (2001)

28. Raymond, W, Freese, Y, Cho, J: Geometry of Linear 2-Normed Spaces. Nova Science Publishers, Huntington (2001)

29. White, A: 2-Banach spaces. Math. Nachr. 42, 43-60 (1969)

30. Savaş, E: $\Delta^{m}$-strongly summable sequence spaces in 2-normed spaces defined by ideal convergence and an Orlicz function. Appl. Math. Comput. 217(1), 271-276 (2010)

31. Savaş, E: A-Sequence spaces in 2-normed space defined by ideal convergence and an Orlicz function. Abstr. Appl. Anal. 2011, Article ID 741382 (2011)

32. Savaş, E: On some new sequence spaces in 2-normed spaces using ideal convergence and an Orlicz function. J. Inequal. Appl. 2010, Article ID 592840 (2010)

33. Şahiner, A, Gürdal, M, Soltan, S, Gunawan, H: Ideal convergence in 2-normed spaces. Taiwan. J. Math. 11(5), 1477-1484 (2007)

34. Dutta, H: Some statistically convergent difference sequence spaces defined over real 2-normed linear space. Appl. Sci. 12, 37-47 (2010)

35. Başar, F, Altay, B: On the space of sequences of $p$-bounded variation and related matrix mappings. Ukr. Math. J. 55(1), 136-147 (2003)

36. Başarır, M, Kayıkçı, M: On the generalized $B^{m}$-Riesz difference sequence space and $\beta$-property. J. Inequal. Appl. 2009, Article ID 385029 (2009)

37. Başarır, M, Kara, EE: On compact operators on the Riesz $B^{m}$ difference sequence spaces. Iran. J. Sci. Technol., Trans. A, Sci. 35(A4), 279-285 (2012)

38. Başarır, M, Kara, EE: On compact operators on the Riesz $B^{m}$ difference sequence spaces II. Iran. J. Sci. Technol., Trans. A, Sci. 4, 279-285 (2011)

39. Başarır, M, Kara, EE: On compact operators and some Euler $B^{m}$ difference sequence spaces. J. Math. Anal. Appl. 379(2), 499-511 (2011)

40. Başarır, M, Öztürk, M: On some generalized $B^{m}$-Riesz sequence spaces and uniform Opial property. J. Inequal. Appl. 2011, Article ID 485730 (2011)

41. Zygmund, A: Trigonometric Series. Cambridge University Press, Cambridge 51(2), 233-239 (2011)

42. Fast, H: Sur la convergence statistique. Colloq. Math. 2, 241-244 (1951)

43. Schoenberg, IJ: The integrability of certain functions and related summability methods. Am. Math. Mon. 66, 361-375 (1959)

44. Fridy, JA: On statistical convergence. Analysis 5, 301-313 (1985)

45. Gürdal, M, Pehlivan, S: Statistical convergence in 2-normed spaces. Southeast Asian Bull. Math. 33, $257-264$ (2009)

doi:10.1186/1029-242X-2013-177

Cite this article as: Başarır et al.: Some generalized difference statistically convergent sequence spaces in 2-normed space. Journal of Inequalities and Applications 2013 2013:177.

\section{Submit your manuscript to a SpringerOpen ${ }^{\circ}$ journal and benefit from:}

- Convenient online submission

Rigorous peer review

- Immediate publication on acceptance

- Open access: articles freely available online

- High visibility within the field

- Retaining the copyright to your article

Submit your next manuscript at $>$ springeropen.com 